\title{
Location of the Gene Specifying Hexose Phosphate Transport (uhp) on the Chromosome of Escherichia coli
}

\author{
By R. C. ESSENBER G \\ Department of Biochemistry, Oklahoma State University, Stillwater, \\ Oklahoma 74074, U.S.A. \\ AND H. L. KORNBERG \\ Department of Biochemistry, University of Cambridge, Cambridge CB2 I $Q W$
}

(Received 28 July 1976)

\section{SUMMARY}

The uhp gene, which specifies the uptake of hexose phosphates, and several other genes in the vicinity of minute $8 \mathrm{I}$ on the $E$. coli linkage map have been located by phage-mediated transductions. The order found is mtl-gpsA-pyrE-gltC-uhp-tnadnaA. Alleles specifying the Uhp- and $\mathrm{Uhp}^{+}$characters were separated from that specifying constitutivity of hexose phosphate uptake $\left(\mathrm{Uhp}^{\mathrm{c}}\right)$. Although cotransduction frequencies between $g l t C$ and $u h p$ as high as $90 \%$, and between $u h p$ and tna as high as $80 \%$, were observed, these frequencies were unusually strongly dependent on which marker was selected. This may be due to the proximity of the $u h p$ region to the point of origin of chromosome replication.

\section{INTRODUCTION}

Hexose phosphates can be used as such by Escherichia coli (Fraenkel, Falcoz-Kelly \& Horecker, 1964; Pogell et al., 1966) and are taken up by the organisms via an inducible, energy-dependent transport system. This system shows several interesting properties, the most unusual being its induction by external, but not internal, glucose 6-phosphate (Heppel, 1969; Dietz \& Heppel, 1971 b; Winkler, 1970, 1971). The uptake of hexose phosphates is coupled to a proton gradient generated either by electron transport or by ATP hydrolysis (Winkler, 1973; Essenberg \& Kornberg, 1975).

These findings were established with the aid of mutants that were either devoid of the uptake system for hexose phosphates (uhp: Kornberg \& Smith, 1969) or constitutive for expression of this system ( $u \mathrm{hp}^{\mathrm{c}}$; Ferenci, Kornberg \& Smith, 1971). The mutants were found to map in the region of minute $8 \mathrm{I}$ on the $E$. coli linkage map as revised by Bachmann, Low \& Taylor (1976) and were about $50 \%$ cotransducible with pyrE. Kadner \& Winkler (1973) confirmed and extended these observations and showed that the $u h p$ locus was on the opposite side of pyrE from the cysE and $m t l$ markers. Kadner (1973) subsequently mapped many alleles in the $u h p$ area and divided the region into a structural and regulatory portion based on whether or not reversions from uhp mutants gave rise to constitutive mutants. $\mathrm{He}$ confirmed the observations of. Ferenci et al. (197r) that constitutive lesions and negative lesions were closely linked, but was not able to determine their orientation directly.

To locate the $u h p$ marker more closely, we studied the cotransduction frequencies of $u h p$ and $u h p^{\mathrm{c}}$ with several other genes in the region of minute $8 \mathrm{r}$ which were not tested by Kadner \& Winkler (1973) and which might be more closely linked to uhp than is pyrE. The results are reported in this paper. 
Table I. Escherichia coli strains used in this study

\begin{tabular}{|c|c|c|}
\hline Strain & Genotype & Source and reference \\
\hline KIO & HfrC & Laboratory stock \\
\hline AT2243 & HfrC metB pyrE & A. L. Taylor \\
\hline 236 & mtlA leu thi & E. C. C. Lin (Solomon \& Lin, 1972) \\
\hline 239 & mtlD mtlC leu thi & E. C. C. Lin (Solomon \& Lin, 1972) \\
\hline CYII5 & gps $A$ metE trpE xyl tsx str & J. E. Cronan, Jr (Cronan \& Bell, 1974) \\
\hline Cs7 & met gltC $\mathrm{c}$ & Y. S. Halpern (Marcus \& Halpern, 1969) \\
\hline AB2 147 & $\begin{array}{l}\text { ilv arg } H \text { met } B \text { his tha gal lac } Y \text { or } Z \text { malA } \\
\quad \text { ara } x y \text { l str ts } x \text { thi } \lambda^{\mathrm{R}} \lambda^{-}\end{array}$ & B. Bachmann (Pittard \& Walker, 1967) \\
\hline EI 77 & $\begin{array}{l}\text { thi thr leu thy } A \text { dra dna } A^{\text {ts }} \text { lac } Y \text { str ton } A \lambda^{-} \\
\text {sup } E\end{array}$ & B. Bachmann (Wechsler \& Gross, I97I) \\
\hline RE2 I & HfrC metB pyrE uhp-40 tna & AT2243 by EMS \\
\hline RE30 & HfrC metB pyrE uhp-4I & AT2243 by EMS \\
\hline RE37 & HfrC metB pyrE uhp-2 & $\begin{array}{l}\text { AT2243, 2-deoxyglucose 6-phosphate } \\
\text { resistant }\end{array}$ \\
\hline AT2243-I I & HfrC metB pyrE uhp ${ }^{\mathrm{c}}$ & AT2243 (Ferenci et al., 197I) \\
\hline RE2IU & HfrC met B uhp-2I tna & RE2 I $\times$ KIO, PyrE + transductant \\
\hline RE3OU & HfrC metB uhp-30 & RE30 $\times$ KIO, PyrE ${ }^{+}$transductant \\
\hline RE37U & HfrC metB uhp-2 & RE37 $\times$ KIO, PyrE + transductant \\
\hline AT2243-I I ${ }^{c} U$ & HfrC metB $u h p^{\mathrm{c}}$ & AT2243-I I $\times \mathrm{KIO}^{\mathrm{C}}, \mathrm{PyrE}^{+}$transductant \\
\hline
\end{tabular}

\section{METHODS}

Media. LB is the tryptone/yeast extract medium described by Luria \& Burrows (I957). Medium 56 (Monod, Cohen-Bazire \& Cohn, I95I) containing thiamin. $\mathrm{HCl}$ at $\mathrm{I} \mu \mathrm{g} \mathrm{ml}^{-1}$ was diluted $\mathrm{I}: 2$ before use and was supplemented with carbon sources at $10 \mathrm{~mm}$ (except glucose 6-phosphate which was used at $5 \mathrm{~mm}$ ). Amino acids, purines and pyrimidines were added, as required, to final concentrations of $100 \mu \mathrm{g} \mathrm{ml}^{-1}$. When used in plates, these media were solidified with $2 \%$ (w/v) agar (Difco).

Bacteria and bacteriophage. The strains of $E$. coli, their genotypes and their sources are listed in Table I. The symbols used for genetical markers are those listed by Bachmann et al. (1976).

Overnight cultures for experiments were started from single colonies. Bacteriophage PI vir was obtained from Dr E. J. Murgola, Section of Molecular Biology, University of Texas, M. D. Anderson Hospital and Tumor Institute, Houston, Texas 77025, U.S.A. It was propagated in chosen strains of $E$. coli and the phage titres were measured by the procedure given by Miller (1972), except that the bacteriophage were grown in organisms plated on LB medium containing $5 \mathrm{mM}-\mathrm{CaCl}_{2}$, using a top agar described by Goldberg, Bender \& Streicher (1974). Bacteriophage PI cml clrioo was obtained from Dr J. L. Rosner, Laboratory of Molecular Biology, National Institute of Arthritis and Metabolic Diseases, National Institutes of Health, Bethesda, Maryland 20014, U.S.A. Lysates and lysogens were prepared as described by Rosner (1972), except that the $40{ }^{\circ} \mathrm{C}$ step in the thermal induction was not used.

Mutagenesis and selection of strains. Two main methods of mutagenesis were employed. Ethyl methanesulphonate (EMS) mutagenesis was performed on strain AT2243 as described by Lin, Lerner \& Jorgensen (I962), whereas the method of Schwartz \& Beckwith (I969) was used when nitrous acid was the mutagen. In most cases, a penicillin-enrichment step (Gorini \& Kaufman, 1960) was interposed before selecting mutants. Mutants were identified either by replica plating, as those showing reduced growth on plates containing 1 mM-glucose 6phosphate as sole carbon source compared with growth on glucose, or by searching for microcolonies on plates containing a mixture of I mM-glucose 6-phosphate and $0.25 \mathrm{~mm}$ glucose. 
We also attempted to isolate $u h p$ mutants by plating cultures of $E$. coli on media containing glycerol and 2-deoxyglucose 6-phosphate (Dietz \& Heppel, 197I $a$ ). Although one such mutant was obtained by this technique (RE37; Table I), the method was less satisfactory than those described above and was abandoned.

Putative mutants revealed by any of these techniques were picked, tested again on the media on which they had been isolated and then purified by repeated isolation of single colonies on LB plates.

Bacteriophage PI transductions. Transductions using either Prvir or PI cml clrioo were performed as described by Miller (1972). For a given lysate, preliminary transductions were done using different dilutions of bacteriophage to determine the ratio of phage to cells which gave most transductants. Further transductions were performed using a single mixture of bacteria and bacteriophage at this ratio, which was plated on as many selective plates as necessary to obtain a sufficient number of recombinants. Sodium citrate was used to prevent re-infection in all cases. Control plates of bacteria alone, and bacteriophage alone, were used for all crosses. After recombinants appeared on the selective plates (usually 2 days at $37^{\circ} \mathrm{C}$ ), they were picked with sterile toothpicks and transferred to fresh selective plates which were grown overnight at $37^{\circ} \mathrm{C}$ : these organisms were then replicated to test for inheritance of the unselected markers. Exceptions to this general procedure are noted in the legends to the Tables.

Analysis of the results of the crosses. In attempting to analyse the four-factor crosses, we found that there was no general procedure for determining the orientations of markers. We therefore developed a technique which also proved useful in the more common three-factor crosses, and was used for all the crosses reported in this paper. Two types of analysis were done on four- and higher-factor crosses. The first was to compute cotransduction frequencies, both between the selected marker and the unselected markers and also between pairs of unselected markers. From the latter, considered in groups of three, one can construct an order as follows. The lowest frequency of cotransduction will occur between the pair of markers furthest apart. These must therefore be the outside two, with the third between. This procedure is rigorous if the selected marker lies between the outermost markers, but sometimes gives misleading results if the selected marker lies well outside this region. From the cotransduction frequencies one can determine which unselected marker is closest to the selected marker, but not on which side it is.

The second type of analysis resolves this ambiguity and alone can provide an order for a three-factor cross. It is an extension of the concept of linkage and is based on the fact that unselected markers on opposite sides of the selected marker generally have no effect on each other's inheritance; thus if the two unselected markers are $A$ and $B$, both $A^{+}$and $A^{-}$ recombinants will show equal ratios of $B^{+} / B^{-}$recombinants, that is $A^{+} B^{+} / A^{+} B^{-}=A^{-} B^{+} /$ $A^{-} B^{-}$. If $A$ and $B$ are on the same side of the selected marker, one class of recombinants between $A$ and $B$ will require four crossovers while the other will require only two, so the ratios of $\mathrm{B}^{+} / \mathrm{B}^{-}$recombinants will not be equal in $\mathrm{A}^{+}$and $\mathrm{A}^{-}$progeny. To test these data for a significant deviation from independent segregation, a $\chi^{2}$ value was calculated, using Yates' (I934) correction, for the $2 \times 2$ contingency table with rows for $\mathrm{A}^{+}$and $\mathrm{A}^{-}$progeny and columns for $\mathrm{B}^{+}$and $\mathrm{B}^{-}$progeny (Mather, $195 \mathrm{I}$ ). The $\chi^{2}$ value was used to give a level of probability which indicates whether the markers are on the same or opposite sides of the selected marker.

Unless otherwise stated, all values deemed significant have a probability of $<\mathrm{I} \%$ of being due to independent segregation. There is one case in which this $\chi^{2}$ value will be high for unselected markers on opposite sides of the selected marker. If the distance between 
the unselected markers is large enough, progeny carrying both markers from the donor are unlikely. This situation should be obvious from cotransduction data. In most cases, the method described here gave the same result as the commonly used method of finding the rarest recombinant class and equating this class with the one requiring four crossovers, and has the advantage of providing a criterion for probability levels for the data. In addition, a few crosses did not give reasonable results based on finding the smallest class of recombinants, but the analysis by our method gave results consistent with other crosses.

\section{RESULTS}

\section{Induction of mutants}

Strains that grew on glucose but not on glucose 6-phosphate were easy to isolate after mutagenesis with ethyl methanesulphonate and enrichment with penicillin. Nitrous acid treatment gave only a small number of mutants, as might be expected from its lower efficiency. Four of these latter mutants were tested by plating them with glucose 6-phosphate as carbon source and with a crystal of $N$-methyl- $N^{\prime}$-nitro- $N$-nitrosoguanidine in the centre of the plate: all showed a halo of growing (and hence $\mathrm{Uhp}^{+}$) colonies, and were thus not deletion mutants, even though nitrous acid is reported to lead to an increased frequency of mutants carrying deletions compared to other treatments (Schwartz \& Beckwith, I969; Alper \& Ames, 1975).

\section{Properties of strains unable to utilize glucose 6-phosphate}

The strains isolated grew on solid media with glucose as carbon source, but not with glucose 6-phosphate; in liquid media, they showed normal growth rates with glucose, gluconate, fructose and glycerol. Growth on glucose 6-phosphate and fructose 6-phosphate was very slow and was probably due to hydrolysis of these hexose phosphates by phosphatases; for the same reason, the mutants grew well on glucose I-phosphate (Dietz \& Heppel, $197 \mathrm{I} c$ ). Washed suspensions of these mutants took up $\left[{ }^{14} \mathrm{C}\right]$ glucose 6-phosphate at initial rates much lower than similar suspensions of the parent organisms, thus confirming that the lesion observed was in hexose phosphate transport.

\section{Mapping of the uhp region}

In preliminary experiments some of the Uhp ${ }^{-}$strains were crossed by conjugation or phage-mediated transduction with a previously described $u h p$ strain (Kornberg \& Smith, 1969) and screened for growth on glucose 6-phosphate. Others were transduced to pyrE ${ }^{+}$ using PI propagated on a prototrophic strain and were again screened for growth on glucose 6-phosphate to determine the cotransduction frequency. These tests failed to bring to light any strain with a lesion in a locus different from that previously described. Strains RE2 I and RE37 were therefore selected as representatives of typical uhp strains for determining the location of $u h p$ with respect to the various markers in the vicinity of minute $8 \mathrm{I}$ on the E. coli genetic map.

These two strains were crossed with the $m t l A$ strain 236 and the $m t l D$ strain 239 (Table 2). Cotransduction between $m t l$ and $u h p$ appears to be very rare; thus, only the cross with $p y r E^{+}$ as the selected marker and strain 236 as donor could be analysed by the normal methods used for three-factor crosses. In both cases, the $\chi^{2}$ value between $m t l$ and $u h p$ showed significant deviation at the 0.05 level. However, the rarest class of recombinants in both cases was that having the donor markers $u \mathrm{hp}^{+}$and $m t l$, so this value must result from the low cotransduction of the two markers rather than their location on the same side of pyrE. Thus 
Mapping of the uhp region

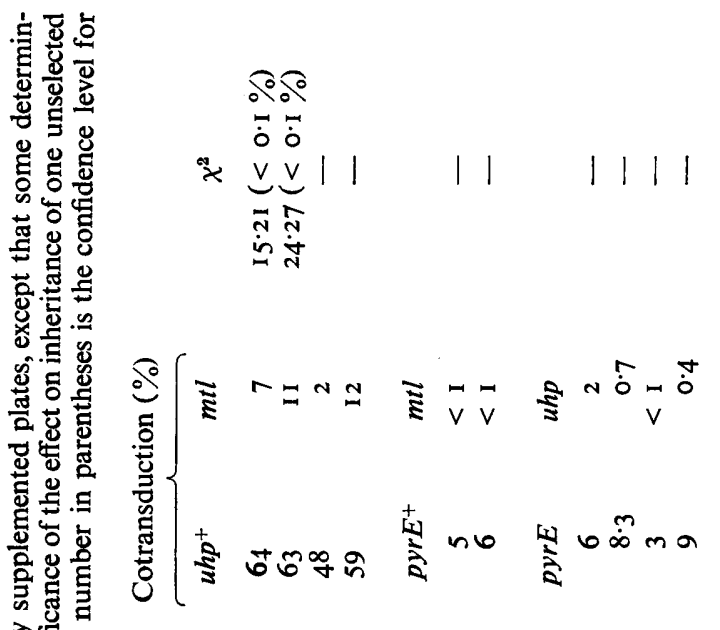

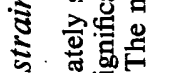

इ

空

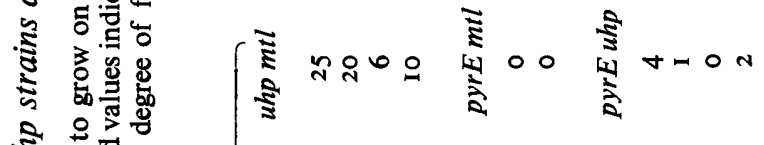

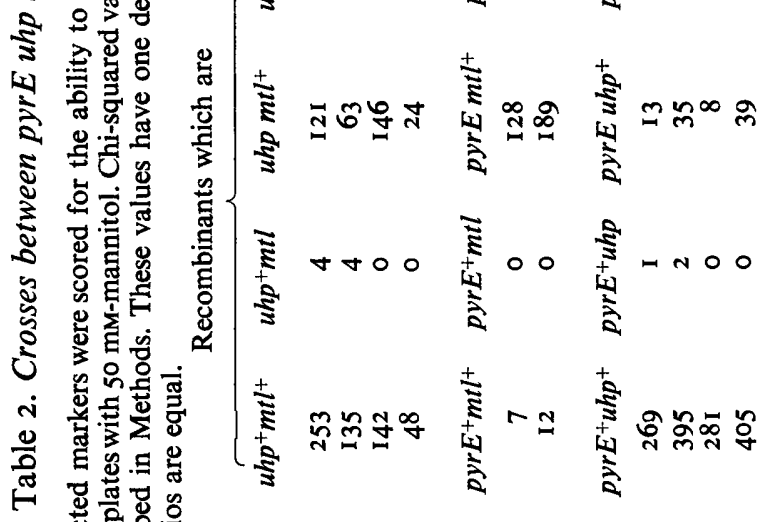

递要要

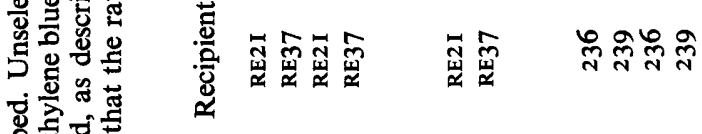

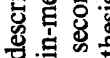

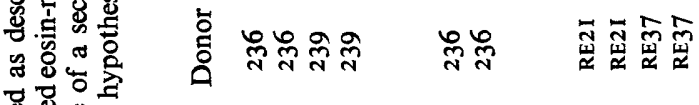

尊密

흥ㅎㅀ

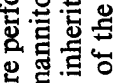

可吉岇

市它要

幽气部

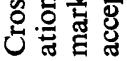

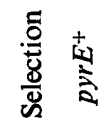

$\frac{5}{5}$ 
递官

啳

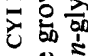

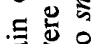

줄

के

氜

密语

苋究

$a_{+}$

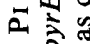

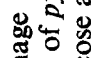

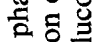

)

อิำ

囦

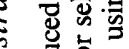

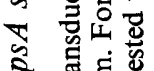

का تृ

典

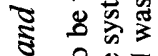

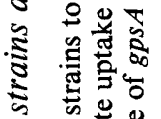

空

唼

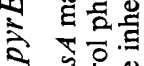

ธ

$\cong \frac{2}{00}$

里

¿ ष

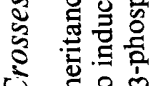

ن 吾递

ल

응

无

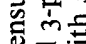

웡

उुं

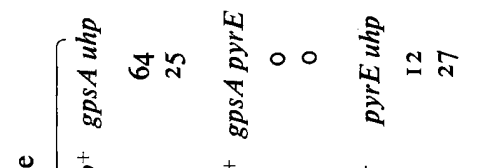

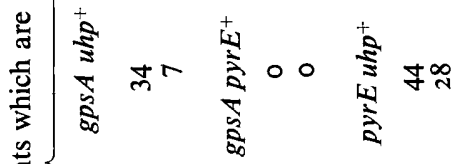

苟

䑻

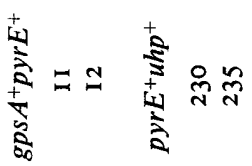

它

हू के

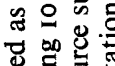

焉.

년 苛 등

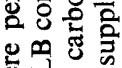

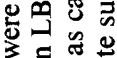

ปี

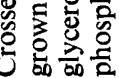

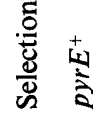

$\stackrel{+}{5}$ 
Table 4. Crosses between strains RE37 and CS7

Crosses were performed as described, using phage PI grown on strain CS7 to transduce RE37. Strains able to grow on glutamate as sole carbon source were scored as $\mathrm{gltC}^{\mathrm{c}}$.

\begin{tabular}{|c|c|c|c|c|c|c|c|c|c|}
\hline $\begin{array}{l}\text { Selected marker and } \\
\text { total no. of } \\
\text { recombinants }\end{array}$ & \multicolumn{2}{|c|}{ pyrE $E^{+}$} & 577 & \multicolumn{2}{|c|}{$u h p^{+}$} & 342 & \multicolumn{2}{|c|}{ GltC $^{c}$} & 850 \\
\hline Unselected markers & gltC & $u h p$ & & pyrE & gltC & & pyrE & uhp & \\
\hline \multirow[t]{4}{*}{ No. of recombinants } & c & + & 415 & + & c & 29 & + & + & 90 \\
\hline & c & - & 49 & + & + & I & + & - & 7 \\
\hline & + & + & 17 & - & c & 172 & - & + & 709 \\
\hline & + & - & 96 & - & + & 140 & - & - & 44 \\
\hline \multirow[t]{2}{*}{ Cotransduction ( $\%)$} & \multirow{2}{*}{\multicolumn{2}{|c|}{$\begin{array}{l}g l t C^{\mathrm{c}} \\
u h p^{+}\end{array}$}} & 80 & \multirow{2}{*}{\multicolumn{2}{|c|}{$\begin{array}{l}\text { pyrE } \\
\operatorname{gltC}^{+}\end{array}$}} & 9 & \multirow{2}{*}{\multicolumn{2}{|c|}{$\begin{array}{c}\text { pyrE } E^{+} \\
u h p^{+}\end{array}$}} & I I \\
\hline & & & 75 & & & 59 & & & 94 \\
\hline$\chi^{2}$ & \multicolumn{2}{|c|}{ gltC-uhp } & $\begin{array}{l}267.308 \\
(<0.1 \%)\end{array}$ & \multicolumn{2}{|c|}{ pyrE-gltC } & $\begin{array}{c}17.812 \\
(<0.1 \%)\end{array}$ & \multicolumn{2}{|c|}{ pyrE-uhp } & $\begin{array}{c}0.288 \\
(<50 \%)\end{array}$ \\
\hline
\end{tabular}

the order indicated in these crosses is $m t$ pyrE uhp, in agreement with the result of Kadner \& Winkler (1973).

Cronan \& Bell (1974) described a mutant requiring glycerol or sn-glycerol 3-phosphate for growth. This lesion, designated gps A, was located between $m t l$ and pyrE. To take advantage of this locus, strains RE2I and RF37 were crossed with strain CYI I5, which carried the gpsA marker (Table 3 ). In the crosses with $p y r E^{+}$as the selected marker $\chi^{2}$ was significant, but the rarest class was the donor phenotype $\mathrm{Gps} \mathrm{A}^{-} \mathrm{Uhp}^{+}$, so this value must again be due to the low cotransduction between gpsA and uhp. The order is therefore gpsA pyrE uhp. The crosses selected for $u h p^{+}$showed no inheritance of $g p s A$, confirming the low cotransduction. However, the crosses selected for $g p s A^{+}$showed measurable cotransduction of $g p s A$ and $u h p$. Again, $\chi^{2}$ values indicated high significance, but in this case inheritance of $u h p$ enhanced that of $p y r E$ which implies that $p y r E$ and $u h p$ are on the same side of $g p s A$. This confirms the order $g p s A$ pyrE uhp because $p y r E^{+} u h p$ recombinants would require four crossovers. The cotransduction frequencies differed depending on which marker was selected. For example, the $p y r E-u h p$ frequency was about $50 \%$ if $p y r E^{+}$was selected, which confirms the results of Kornberg \& Smith (1969), but was only $5 \%$ if $u h p^{+}$was selected. This difference was also observed for gpsA-uhp crosses, but it was not apparent for gpsA-pyrE.

The $g l t C^{\mathrm{c}}$ mutation described by Marcus \& Halpern (1969) permits $E$. coli KI 2 strains to grow at $37^{\circ} \mathrm{C}$ on glutamate as sole carbon source: wild-type $\mathrm{KI} 2$ strains do not. This marker

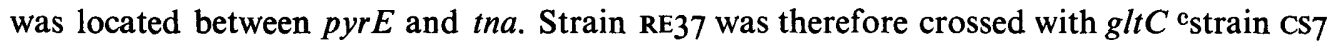
(Table 4). With $p y r E^{+}$as the selected marker, highly significant $\chi^{2}$ values were observed for the effect of $u h p$ inheritance on $g l t C$ inheritance. Inheritance of $u h p^{+}$enhanced inheritance of gltC $C^{\mathrm{c}}$, which implies that the order is pyrE gltC uhp. When $u h p^{+}$was selected, similarly significant effects were seen, with inheritance of $p y r E^{+}$enhancing that of $g l t C^{c}$. This result also implies the order pyrE gltC uhp. Finally, when $g l t C^{\mathrm{c}}$ was the marker selected, there was no significant effect of pyrE inheritance on $u h p$ inheritance, which implies that the unselected markers are on opposite sides of $g l t C$, in agreement with the other results. It is noteworthy that $g l t C^{\mathrm{c}}$ and $u h p$ are $94 \%$ cotransducible, if $g l t C^{\mathrm{c}}$ is selected. This cross shows unequal cotransduction frequencies in reciprocal crosses as do those involving gps $A$.

The gene governing the activity of the enzyme tryptophanase, tna, is located on the $E$. coli linkage map between gltC and phoS (Bachmann et al., 1976). Strain AB2 I47, carrying the tna lesion, was crossed with strain RE37 (Table 5). As expected, tna appears to be closer to 


\section{Table 5. Crosses between strains RE37 and AB2I47}

Crosses were performed as described, using phage PI grown on AB2147 to transduce RE37. The method of Pittard \& Walker (1967) was used to score Tna.

\begin{tabular}{|c|c|c|c|}
\hline $\begin{array}{l}\text { Selected marker and total no. } \\
\text { of recombinants }\end{array}$ & \multicolumn{2}{|c|}{ pyrE $E^{+}$} & 712 \\
\hline Unselected markers & uhp & tna & \\
\hline \multirow[t]{4}{*}{ No. of recombinants } & + & + & 442 \\
\hline & + & - & I5 \\
\hline & - & + & $25 \mathrm{I}$ \\
\hline & - & - & 4 \\
\hline \multirow[t]{2}{*}{ Cotransduction $(\%)$} & \multicolumn{2}{|c|}{$u h p^{+}$} & 64 \\
\hline & \multicolumn{2}{|c|}{ tna } & 3 \\
\hline$\chi^{2}$ & \multicolumn{2}{|c|}{$u h p-t n a$} & $\begin{array}{l}I \cdot 250 \\
<30 \%\end{array}$ \\
\hline
\end{tabular}

\begin{tabular}{|c|c|c|}
\hline \multicolumn{2}{|c|}{$u h p^{+}$} & 555 \\
\hline pyrE & tha & \\
\hline+ & + & 38 \\
\hline+ & - & 3 \\
\hline- & + & 388 \\
\hline- & - & I 26 \\
\hline & & $\begin{array}{r}7 \\
23\end{array}$ \\
\hline pyr & & $\begin{array}{c}5.367 \\
(<5 \%)\end{array}$ \\
\hline
\end{tabular}

Table 6. Crosses between strains RE37 and EI 77

Crosses were performed as described, using phage PI grown on the strain indicated as donor. In the crosses with EI 77 as donor, selective plates were incubated at $30^{\circ} \mathrm{C}$ so as not to select against inheritance of dnaA. Recombinants that did not grow at $42{ }^{\circ} \mathrm{C}$ were scored as DnaA-.

\begin{tabular}{|c|c|c|c|c|c|c|c|c|c|}
\hline \multirow{2}{*}{$\begin{array}{l}\text { Donor } \\
\text { Recipient } \\
\text { Selected marker and } \\
\text { total no. of } \\
\text { recombinants }\end{array}$} & \multicolumn{2}{|c|}{$\begin{array}{l}\text { EI77 } \\
\text { RE37 }\end{array}$} & \multicolumn{4}{|c|}{ EI 77} & \multicolumn{2}{|c|}{ RE37 } & \\
\hline & \multicolumn{2}{|c|}{$\operatorname{pyr} E^{+}$} & 209 & \multicolumn{2}{|c|}{$u h p^{+}$} & $43 I$ & \multicolumn{2}{|c|}{$\operatorname{dna} A^{+}$} & $43 \mathrm{I}$ \\
\hline Unselected markers & $u h p$ & $\operatorname{dnaA}$ & & pyrE & $\operatorname{dna} A$ & & pyrE & $u h p$ & \\
\hline No. of recombinants & $\begin{array}{l}+ \\
+ \\
-\end{array}$ & $\begin{array}{l}+ \\
- \\
+ \\
-\end{array}$ & $\begin{array}{r}126 \\
0 \\
77 \\
6\end{array}$ & $\begin{array}{l}+ \\
+ \\
- \\
-\end{array}$ & $\begin{array}{l}+ \\
- \\
+ \\
-\end{array}$ & $\begin{array}{r}51 \\
15 \\
333 \\
32\end{array}$ & $\begin{array}{l}+ \\
+ \\
- \\
-\end{array}$ & $\begin{array}{l}+ \\
- \\
+\end{array}$ & $\begin{array}{r}329 \\
100 \\
2 \\
0\end{array}$ \\
\hline Cotransduction $(\%)$ & \multicolumn{2}{|c|}{$\begin{array}{l}u h p^{+} \\
d n a A\end{array}$} & $\begin{array}{r}60 \\
3\end{array}$ & $\begin{array}{r}\text { pyr } \\
d n c\end{array}$ & & $\begin{array}{l}\text { I5 } \\
\text { II }\end{array}$ & \multicolumn{2}{|c|}{$\begin{array}{c}\text { pyrE } \\
\text { uhp }\end{array}$} & $\begin{array}{l}0.5 \\
23\end{array}$ \\
\hline$\chi^{2}$ & \multicolumn{2}{|c|}{$u h p-d n a A$} & $\begin{array}{c}6.96 \\
(<1 \%)\end{array}$ & pyrE & $d n a A$ & $\begin{array}{c}1 \mathrm{I} \cdot 2 \mathrm{I} \\
(<0.1 \%)\end{array}$ & \multicolumn{2}{|c|}{ pyrE-uhp } & - \\
\hline
\end{tabular}

uhp than to $p y r E$, the cotransduction frequencies being 23 and $3 \%$, res pectively. The $\chi^{2}$ value for the effect of $u h p$ inheritance on tna inheritance in the cross selected for $p y r E^{+}$was not highly significant, probably due to the smaller cotransduction between $p y r E$ and tna. The order can be deduced from cotransduction frequencies as pyrE uhp tna. In the cross where $u h p^{+}$was selected, the $\chi^{2}$ value showed a significant effect because of the improbability of inheritance of both $p y r E^{+}$and tna from the donor (3/555 colonies tested). Again, cotransduction frequencies were not equal for the two possible selections.

A gene governing initiation of DNA synthesis, dnaA, has been provisionally located between tha and phoS (Wechsler \& Gross, 1971). Strain EI77, carrying a temperature-sensitive lesion in $d n a A$, was crossed with strain RE37 (Table 6). There was very little cotransduction between $p y r E$ and $d n a A$ in either direction. As expected, cotransduction frequencies between $d n a A$ and $u h p$ indicate that $d n a A$ is farther from $u h p$ than is tna. Because of the low cotransduction frequencies observed, $\chi^{2}$ values would not be meaningful, and were not calculated.

Strain RE2 I was unexpectedly found to be tha. Crosses with AB2 I47 indicated that this tna allele was at the same locus as that in AB2I47, so RE2I was used in crosses with CS7 to con- 
Table 7. Crosses between strains RE2I and CS7

Crosses were performed as described, using PI grown on strain CS7 to transduce RE2I. Recombinants able to utilize glutamate as sole carbon source were scored as GltCe.

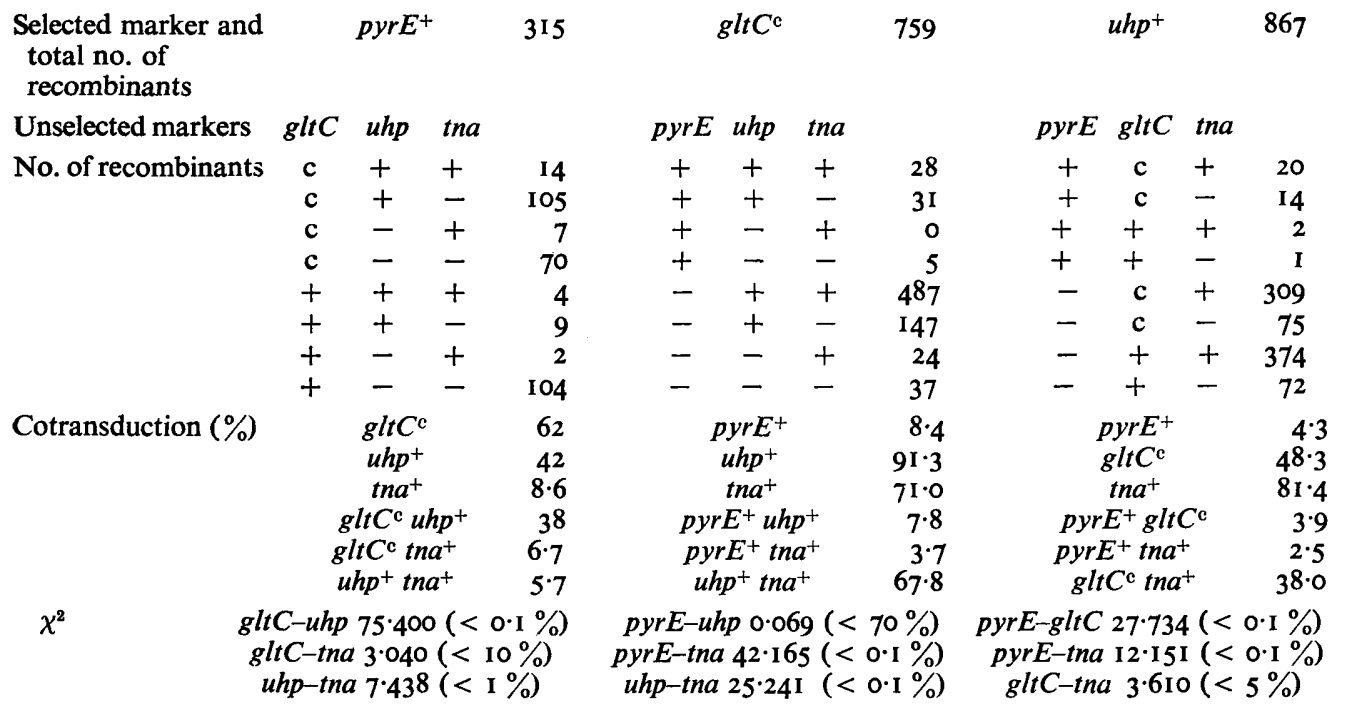

firm the order between $g l t C$, uhp and tha, since all three would be present in the same cross. The results are shown in Table 7 . In the selection for $p y r E^{+}$, the cotransduction frequencies decreased in the order $g l t C>u h p>t n a$. Further, $g l t C$ and $u h p$ had a significant effect on each other, as did uhp and tna. The order indicated is pyrE gltC uhp tna. In the selection for $\mathrm{glt} \mathrm{C}^{\mathrm{c}}$, the order of cotransduction frequencies of unselected markers subsequently scored is $u h p>t n a>p y r E$. Double cotransductions indicated that, of these three markers, uhp and tna are closest and $p y r E$ and $t n a$ are farthest apart, which again supports the order $p y r E$ uhp tna. The lack of effect of $p y r E$ on $u h p$ indicates that $g l t C$ falls between these markers, so the overall order measured in this manner is also pyrE gltC uhp tna. In the selection for $u h p^{+}$, double cotransduction frequencies give the order $p y r E$ gltC tha, and uhp must be between $g l t C$ and $t n a$, because of cotransduction frequencies and the lack of significant effects between these markers.

\section{Fine structure mapping}

To estimate the extent of the $u h p$ region and to get some idea of the relative location of mutations giving rise to constitutive and negative mutants, a series of crosses between negative strains or between negative and constitutive strains was done. The order of the lesions can sometimes be deduced in such a series of crosses, using results from reciprocal crosses. The strains used for this series were all $p y r E$, so the most convenient selection was for $p y r E^{+}$. Accordingly each strain was transduced to $p y r E^{+}$using phage grown on wildtype Kro cells. Strains were tested for retention of the original uhp mutations. These $p y r E^{+}$ strains were then used as donors in crosses in various combinations with the $p y r E$ strains (Table 8). In all cases, recombinants of the phenotype expected from crossovers between the lesions were observed, indicating that the lesions were at different sites. 


\section{Table 8. Fine structure mapping of uhp and uhp strains}

Transductions were performed as described, selecting for growth in the absence of uracil in all cases. For crosses between negative strains, $\mathrm{Pyr}^{+}$selective plates were replicated on to plates containing glucose 6phosphate as sole carbon source and the total number of $\mathrm{Pyr}^{+}$and $\mathrm{Pyr}^{+} \mathrm{Uhp}^{+}$recombinants was counted. For crosses between AT2243-I I ${ }^{\mathrm{C}}$ or AT2243-I I ${ }^{\mathrm{C}} \mathrm{U}$ and the negative strains, $\mathrm{Pyr}^{+}$transductants were transferred using sterile toothpicks on to plates containing either glucose 6-phosphate or fructose I-phosphate as sole carbon source. By comparison of these plates, $\mathrm{Uhp}^{+}$(not $\mathrm{Uhp}^{\mathrm{c}}$ ) strains were scored. The value of $\chi^{2}$ is calculated from the $2 \times 2$ contingency table whose rows are the two reciprocal crosses, and whose columns are recombinants $\left(\mathrm{Uhp}^{+}\right.$) versus non-recombinants (Uhp ${ }^{-}$or $\mathrm{Uhp}^{\mathrm{c}}$ ) for the region between the two mutations. This value has one degree of freedom.

\begin{tabular}{|c|c|c|c|c|c|}
\hline \multirow[b]{3}{*}{ Donor } & \multirow[b]{3}{*}{ Recipient } & \multicolumn{3}{|c|}{ Recombinants } & \multirow[b]{3}{*}{$\chi^{2}$} \\
\hline & & \multicolumn{2}{|c|}{ Number } & Percentage & \\
\hline & & Pyr $^{+}$ & Uhp $^{+}$ & Uhp $^{+} /$Pyr $^{+}$ & \\
\hline $\begin{array}{l}\text { RE2IU } \\
\text { RE3OU }\end{array}$ & $\begin{array}{l}\text { RE3O } \\
\text { RE2 I }\end{array}$ & $\begin{array}{l}562 \\
379\end{array}$ & $\begin{array}{r}22 \\
6\end{array}$ & $\left.\begin{array}{l}3.9 \\
1.6\end{array}\right\}$ & $4.26(<5 \%)$ \\
\hline $\begin{array}{l}\text { RE2IU } \\
\text { RE37U }\end{array}$ & $\begin{array}{l}\text { RE37 } \\
\text { RE2 I }\end{array}$ & $\begin{array}{l}884 \\
759\end{array}$ & $\begin{array}{r}18 \\
4\end{array}$ & $\left.\begin{array}{l}2.0 \\
0.5\end{array}\right\}$ & $7.04(<1 \%)$ \\
\hline $\begin{array}{l}\text { RE3OU } \\
\text { RE37U }\end{array}$ & $\begin{array}{l}\text { RE37 } \\
\text { RE30 }\end{array}$ & $\begin{array}{l}1427 \\
1740\end{array}$ & $\begin{array}{l}14 \\
17\end{array}$ & $\left.\begin{array}{l}1 \cdot 0 \\
1 \cdot 0\end{array}\right\}$ & $0.00013(<99 \%)$ \\
\hline $\begin{array}{l}\text { AT2243-1 I }{ }^{\mathrm{C} U} \\
\text { RE2 IU }\end{array}$ & $\begin{array}{l}\text { RE2I } \\
\text { AT2243-I I }\end{array}$ & $\begin{array}{l}94 \mathrm{I} \\
984\end{array}$ & $\begin{array}{l}5 \\
9\end{array}$ & $\begin{array}{l}0.5 \\
0.9\end{array}$ & $0.98(<50 \%)$ \\
\hline $\begin{array}{l}A^{\prime} 2243-1 I^{C} U \\
R E 37 U\end{array}$ & $\begin{array}{l}\text { RE37 } \\
\text { AT2243-I I }^{c}\end{array}$ & $\begin{array}{l}854 \\
830\end{array}$ & $\begin{array}{r}9 \\
19\end{array}$ & $\left.\begin{array}{l}I \cdot I \\
2 \cdot 3\end{array}\right\}$ & $3.94(<5 \%)$ \\
\hline
\end{tabular}

DISCUSSION

From the results presented here, it is possible to construct a detailed map of the $E$. coli genome in the vicinity of minute $8 \mathrm{I}$ (Fig. I). The $u h p$ gene lies between gltC and tna and, from the cotransduction frequencies, appears to be quite close to $g l t C$, possibly adjacent. These results are in substantial agreement with those of Kadner \& Winkler (1973), who placed $u h p$ between $p y r E$ and $b g l$. There are some small discrepancies: Kadner \& Winkler ( 1973) reported the cotransduction frequency of $p y r E$ and $u h p$ to be between 29 and $46 \%$, whereas we find a range of 42 to $75 \%$. This may simply be a strain difference, or could result from slightly different procedures for the transduction experiments. Also, the striking asymmetry in cotransduction frequencies, which depends on the end of the interval at which the selected marker lies, does not appear to have been observed previously.

This lack of reciprocity in the cotransduction frequencies appears to be most pronounced in the region of $u h p$, and was manifested by all cotransductions with $u h p$. However, it was also obtained in several cotransductions which do not involve $u h p$ (as, for example, the cotransductions pyrE-gltC and $g l t C-d n a A)$ and so is not associated uniquely with $u h p$. In most cases, the cross with the selected marker counterclockwise from the unselected one gave the higher frequency, but in the case of $u h p-d n a A$, the reverse was observed. In all cases involving $u h p$, the frequency observed in the cross where it was the selected marker was lower. This was not due to reversion of $u h p$, since no revertants grew on the control plates; moreover, the same result was obtained with two independent $u h p$ mutants. The origin of replication of the chromosome is in the region between $b g l$ and $m t l$ (Masters, 1975) and thus very close to uhp: this location may lead to favoured sites of chromosome breakage, which could explain the results.

Construction of a fine structure map on the basis of the results presented in Table 8 poses some difficulties. The placement of the negative lesions is relatively easy since the orders 


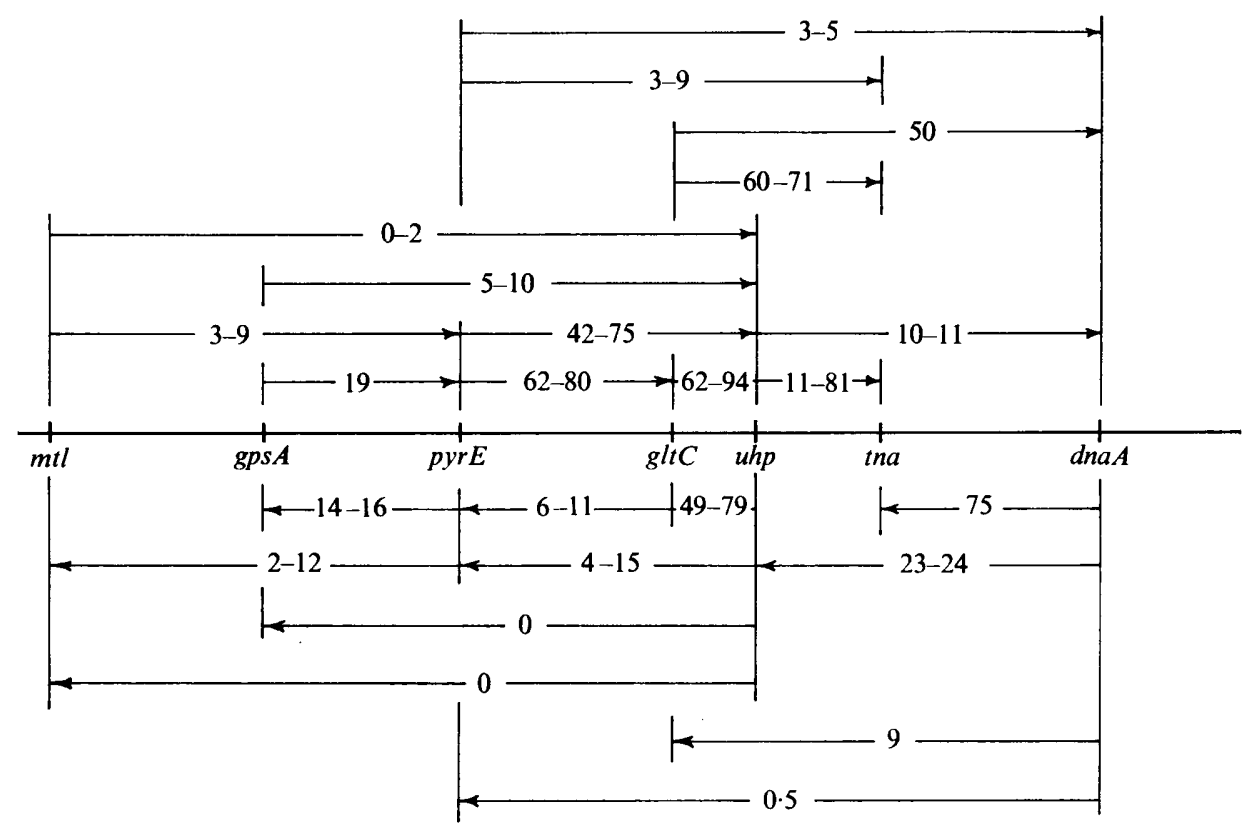

Fig. I. Map of the $E$. coli chromosome in the region of minute 81 . The order indicated is that deduced from the crosses presented although, for the sake of brevity, no data are given in this paper for the transductions dnaA-tna, dnaA-gltC and $g l t C-d n a A$. The figures are the contransduction frequencies observed. Where a range is indicated, the numbers are the maximum and minimum for all crosses. Frequencies above the line had the marker on the left as the selected marker, those below had the marker on the right.

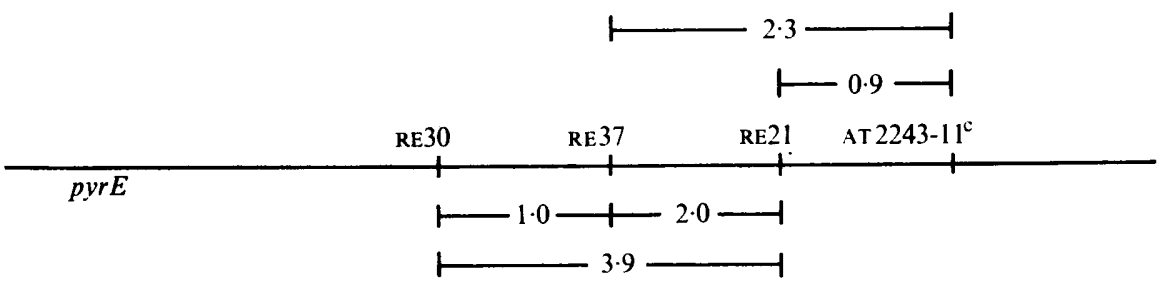

Fig. 2. Fine structure map of the $u h p$ region. Negative lesions are ordered according to the data from the reciprocal crosses where consistent with recombination frequencies. The constitutive allele is located using the observed recombination frequencies. Distances indicated are the highest observed percentage of pyrE $E^{+}$recombinants which were recombinant in the region between the lesions.

deduced from the differences between results from reciprocal crosses are consistent with the distance based on recombination frequencies. However, the $u \mathrm{hp}^{\mathrm{c}}$ lesion cannot be placed without disregarding either the distance data or the order data. It seems more likely that the distance data are correct, especially since the significance of the differences between the reciprocal crosses is low or non-existent. Using the distance data, one obtains the map shown in Fig. 2. The distances are nearly additive, and $u h p^{\mathrm{c}}$ is on the distal side of the $u h p$ region from pyrE, as proposed by Kadner (1973). Taking the minimum distance, or the average, rather than the maximum, the additivity is even better. Negative interference could lead to equal frequencies in the reciprocal crosses, and would be more pronounced with a relatively distant marker, such a $p y r E$. Use of a closer marker such as $g l t C$ could resolve this problem. 
The capable technical assistance of Kathleen Brown, Kathal Bales and Theresa Mason is gratefully acknowledged. We also thank Drs B. Bachmann, J. E. Cronan, Jr, Y. S. Halpern, E. C. C. Lin, E. J. Murgola, and J. L. Rosner for generous gifts of bacteria and bacteriophage. Dr M. C. Jones-Mortimer suggested the method of analysis of the crosses, and aided us with much helpful discussion.

This work was supported in part by grant number B/SR/72462 from the Science Research Council. Part was done while R.C.E. was supported by National Institutes of Health postdoctoral fellowship 5FO2 AM47162-02.

This is journal article J-3503 of the Oklahoma Agricultural Experiment Station.

\section{REFERENCES}

AlPER, M. D. \& Ames, B. N. (1975). Positive selection of mutants with deletions of the gal-chl region of the Salmonella chromosome as a screening procedure for mutagens that cause deletions. Journal of Bacteriology 121, 259-266.

BACHMANN, B. J., Low, K. B. \& TAYLOR, A. L. (1976). Recalibrated linkage map of Escherichia coli K-I2. Bacteriological Reviews 40, I I6-I67.

Cronan, J. E., JR \& Bell, R. M. (1974). Mutants of Escherichia coli defective in membrane phospholipid synthesis: mapping of the structural gene for L-glycerol-3-phosphate dehydrogenase. Journal of Bacteriology 118, 598-605.

Dietz, G. W. \& HePpel, L. A. (I97I $a$ ). Studies on the uptake of hexose phosphates. I. 2-Deoxyglucose and 2-deoxyglucose-6-phosphate. Journal of Biological Chemistry 246, 288I-2884.

Dietz, G. W. \& HePpel, L. A. (I97I $b$ ). Studies on the uptake of hexose phosphates. II. The induction of the glucose-6-phosphate transport system by exogenous but not by endogenously formed glucose-6-phosphate. Journal of Biological Chemistry 246, 2885-2890.

DieTz, G. W. \& HePpel, L. A. (197I c). Studies on the uptake of hexose phosphates. III. Mechanism of uptake of glucose-I-phosphate in Escherichia coli. Journal of Biological Chemistry 246, 289I-2897.

EssenberG, R. C. \& KornberG, H. L. (I975). Energy coupling in the uptake of hexose phosphates by Escherichia coli. Journal of Biological Chemistry 250, 939-945.

Ferenci, T., Kornberg, H. L. \& SMith, J. (197I). Isolation and properties of a regulatory mutant in the hexose phosphate transport system of Escherichia coli. FEBS Letters 13, I33-136.

Fraenkel, D. G., Falcoz-Kelly, F. \& Horecker, B. L. (1964). The utilization of glucose-6-phosphate by glucokinaseless and wild-type strains of E. coli. Proceedings of the National Academy of Sciences of the United States of America 52, 1207-1213.

Goldberg, R. B., Bender, R. A. \& Streicher, S. L. (I974). Direct selection for Pi-sensitive mutants of enteric bacteria. Journal of Bacteriology $118,810-814$.

Gorini, L. \& KaUfman, H. (1960). Selecting bacterial mutants by the penicillin method. Science 131, 604605.

HePpeL, L. A. (I969). The effect of osmotic shock on release of bacterial proteins and on active transport. Journal of General Physiology 54, 95s-I09s.

KADNER, R. J. (1973). Genetic control of the transport of hexose phosphates in Escherichia coli. Journal of Bacteriology I16, 764-770.

KADNER, R. J. \& WINKLER, H. H. (1973). Isolation and characterization of mutations affecting the transport of hexose phosphates in Escherichia coli. Journal of Bacteriology 113, 895-900.

Kornberg, H. L. \& SMITH, J. (1969). Genetic control of hexose phosphate uptake by Escherichia coli. Nature, London 224, I 261-I 262.

Lin, E. C. C., Lerner, S. A. \& Jorgensen, S. E. (I962). A method for isolating constitutive mutants for carbohydrate-catabolizing enzymes. Biochimica et biophysica acta 6o, 422-424.

Luria, S. E. \& Burrows, J. W. (1957). Hybridization between Escherichia coli and Shigella. Journal of Bacteriology 74, 46I-476.

MARCUS, M. \& HALPERN, Y. S. (1969). Genetic analysis of the glutamate permease in Escherichia coli K12. Journal of Bacteriology 97, 1 I $18-1128$.

MASTERS, M. (1975). Strains of Escherichia coli diploid for the chromosomal origin of DNA replication. Molecular and General Genetics 143, 105-I I I.

MATHER, K. (195I). The Measurement of Linkage in Heredity. London: Methuen.

Mrller, J. H. (1972). Experiments in Molecular Genetics. Cold Spring Harbor, New York: Cold Spring Harbor Laboratory.

Monod, J., Cohen-Bazire, G. \& Cohn, M. (I95I). Sur la biosynthèse de la $\beta$-galactosidase (lactase) chez $E$. coli. La specificité de l'induction. Biochimica et biophysica acta 7, 585-599. 
PITTARD, J. \& WALKER, E. M. (1967). Conjugation in Escherichia coli: recombination events in terminal regions of deoxyribonucleic acid. Journal of Bacteriology 94, I656-1663.

Pogell, B. M., Marty, B. R., Frumkin, S. \& Shapiro, S. (1966). Induction of an active transport system for glucose-6-phosphate in Escherichia coli. Archives of Biochemistry and Biophysics 116, 406-415.

ROSNER, J. L. (1972). Formation, induction, and curing of bacteriophage PI lysogens. Virology 48, 679-689.

SChWARTZ, D. O. \& BeCKWITH, J. R. (1969). Mutagens which cause deletions in Escherichia coli. Genetics 6I, $37 \mathrm{I}-376$.

Solomon, E. \& LiN, E. C. C. (1972). Mutations affecting the dissimilation of mannitol by Escherichia coli K-12. Journal of Bacteriology III, 566-574.

WECHSLER, J. A. \& GROSS, J. D. (197I). Escherichia coli mutants temperature-sensitive for DNA synthesis. Molecular and General Genetics $113,273-284$.

WINKLER, H. H. (1970). Compartmentation in the induction of the hexose-6-phosphate transport system of Escherichia coli. Journal of Bacteriology 101, 470-475.

WINKLER, H. H. (197I). Kinetics of exogenous induction of the hexose-6-phosphate transport system of Escherichia coli. Journal of Bacteriology 107, 74-78.

WINKLER, H. H. (1973). Energy coupling of the hexose phosphate transport system in Escherichia coli. Journal of Bacteriology II6, 203-209.

YATES, F. (1934). Contingency tables involving small numbers and the $\chi^{2}$ test. Journal of the Royal Statistical Society, Supplement I, 217-235. 